\title{
Development of Medical Devices: Advantages of a Methodic Approach
}

\author{
Isa C.T. Santos ${ }^{1}$, G. Scott Gazelle ${ }^{2}$, Luís A. Rocha ${ }^{3}$ and João Manuel R.S. Tavares ${ }^{1}$ \\ ${ }^{1}$ Faculty of Engineering, University of Porto / Institute of Mechanical Engineering and Industrial Management, Porto, Portugal \\ ${ }^{2}$ Institute for Technology Assessment and Department of Radiology,Massachusetts General Hospital, Harvard Medical School, \\ 101 Merrimac St, 10th Floor, Boston, MA 02114-4724, USA, Department of Health Policy and Manage-ment, \\ Harvard School of Public Health, Boston, MA, USA \\ ${ }^{3}$ Institute for Polymers and Composites / I3N, University of Minho, Guimarães, Portugal
}

\begin{abstract}
It is possible to advocate that, as far as complexity is concerned, the medical devices sector is comparable to the aviation and nuclear industries. Some of the arguments used are the broad definition of the term "medical device", the multiplicity of regulations and the nature of the relation between manufacturers and users. In such environment, the uncertainty associated to the development of novel devices is high and justifies the use of dedicated methodologies. In general, the application of product development methodologies helps to reduce the duration of the tasks, optimize the available resources and obtain products and/or services that please customers. In the case of medical devices, the authors believe that resorting to such methodologies is crucial to overcome the industry's complexity without losing competitiveness. The product development process involves the following steps: identification of an opportunity, voice of the customer, concept development, design, test and validation and launch. This paper describes each one of the aforementioned stages and suggests adaptations to the healthcare sector.
\end{abstract}

Keywords - Product development, Optimization, Decision, Review, Public health regulation and supervision

\section{INTRODUCTION}

According to the World Health Organization (WHO), there are around 1.5 million different medical devices [1]. At first glance, this number is overwhelming but, considering that the term "medical device" includes apparatuses ranging from simple tongue depressors to drug-eluting stents or engineered tissues, the figure seems reasonable. The definition of "medical device" is one of the features that makes this sector complex. Other aspects are the multiplicity of regulations that medical devices have to comply with and the existence of motley agencies that evaluate devices before commercialization. The characteristics that make the medical device's industry complex are detailed in this paper. In addition, it presents the traditional approach to product development and the authors show how a dedicated methodology can contribute to the reduction of costs during the development of new products while increasing the device's acceptance by its users, i.e., the actual use of the device / service.

\section{Materials And Methods}

In recent years, the number of publications regarding product development methodologies has increased. However, few are dedicated to medical devices. Thus, the information presented here was retrieved not only from books and scientific journals but also from web pages of governments and agencies responsible for protecting and promoting public health through regulation and supervision.

Data from the WHO indicates the European Union (EU) and US as responsible for more than $50 \%$ of the manufacture of medical devices [2]. In this work, only the regulations and agencies from these countries are considered.

\section{RESULTS}

\section{A. Definition and classification of medical devices}

As a general rule, the expression "medical device" refers to any apparatus, software, material or other similar or related article, intended to be used in the diagnosis, prevention, monitoring, treatment or alleviation of a disease or an injury. In the US, the definition appears in section 201(h) of the "Food Drug \& Cosmetic Act", while in Europe, it is given by the "Medical Devices Directive 93/42/EEC".

Medical devices can be categorized as preventive, diagnostic, therapeutic and assistive, according to the stage of health care in which they are used. It is also possible to distinguish between medical devices for general use (e.g. thermometer, stethoscope) and disease-specific. However, this categorization is merely organizational. The classification, on the other hand, defines the medical device's path to market.

The classification of medical devices in done according to a series of factors, including the risk it poses to both user and operator in case of failure and the time it is intended to be in continuous use. The US defined three classes while EU defined four (Table 1). 
In the US, medical devices are regulated by the Center for Devices and Radiological Health (CDRH) of the FDA (Food and Drug Administration). Although, this governmental agency uses third parties for the preliminary assessment of low- and medium-risk devices, it retains final authority over all devices' approval. In EU, the pre-market review and approval is conducted by independent thirdparty testing laboratories, named notified bodies, accredited by Member State Health Ministries.

Table 1 Medical device classification and requirements for market clearance in the US and EU

\begin{tabular}{|c|c|c|c|}
\hline System & Class & Examples & $\begin{array}{l}\text { Requirements for market } \\
\text { clearance }\end{array}$ \\
\hline \multirow{3}{*}{ US } & I & $\begin{array}{l}\text { Adhesive bandages } \\
\text { Hospital beds }\end{array}$ & General controls \\
\hline & II & $\begin{array}{l}\text { Blood pressure cuffs } \\
\text { Sutures }\end{array}$ & $\begin{array}{l}\text { General Controls and Specia } \\
\text { Controls }\end{array}$ \\
\hline & III & $\begin{array}{l}\text { Pacemaker } \\
\text { Vascular graft }\end{array}$ & $\begin{array}{l}\text { General Controls and Pre- } \\
\text { market Approval (PMA) }\end{array}$ \\
\hline \multirow{4}{*}{$\mathrm{EU}$} & I & $\begin{array}{l}\text { Surgical gauze } \\
\text { Wheelchairs }\end{array}$ & $\begin{array}{l}\text { Self-certifiable } \\
\text { CE marking }\end{array}$ \\
\hline & IIa & $\begin{array}{l}\text { Hearing aids } \\
\text { Ultrasound equipment }\end{array}$ & \multirow{3}{*}{$\begin{array}{l}\text { Assessment by a Notified } \\
\text { Body } \\
\text { CE marking }\end{array}$} \\
\hline & $\mathrm{IIb}$ & $\begin{array}{l}\text { Infusion pumps } \\
\text { Surgical lasers }\end{array}$ & \\
\hline & III & $\begin{array}{l}\text { Prosthetic joints } \\
\text { Stent-grafts }\end{array}$ & \\
\hline
\end{tabular}

\section{B. Path to market}

A medical device to be commercialized in EU has to present a CE mark. In order to obtain it, the manufacturer has to demonstrate and document compliance with the regulations and issue a declaration of conformity. In certain situations, such as class I sterile devices, it may be required the intervention of a Notified Body, which, in general, is a profit-driven organization and charges fees for its services. Class III devices require clinical studies, except when data already exists. The evaluation process may take between three days to several months depending on the class of the device, the size of the manufacturer, the size of the technical file and the duration of the clinical study.

In the US, the CDRH is responsible for the pre-market assessment of new medical devices. Low risk (class I) devices are subject to certain general controls, such as requirements for labeling and good manufacturing practices. Most of them are not required to undergo the pre-market clearance through the $510(\mathrm{k})$ process, i.e., a 90-day review process based on the argument that the device is equivalent to one that was already approved by the FDA. Class II devices, in addition to general controls, have to comply with special controls, namely performance standards, guidance documents or implementation of post-market surveillance. Class III medical devices are subject to Premarket Approval Application (PMA), the most stringent evaluation. This process can take between 6 months to 2 years, depending on factors such as the report of clinical studies and quality of documents. The Human Device Exemption (HDE) is a specific path for class III medical devices designed to address diseases and conditions that affect fewer than 4000 patients / year.

\section{Post- market surveillance}

Since medical devices involve human safety, manufacturers have two obligations when they deliver a device to the market: post-market surveillance and adverse event reporting. The first allows the detection of rare but serious adverse events and long-term failures that are unable to detect during the pre-market surveillance due to the short duration of the clinical studies and / or the limited number of participants.

The data gathered during this period is important to monitor the device's safety and effectiveness. Furthermore, it helps determining if the device merits coverage from governments and / or reimbursement agencies and assessing the effectiveness and cost-effectiveness beyond that required for entering the market.

In order to issue alerts or recalls for unsafe or ineffective items, manufacturers are also obliged to keep trace of the devices sold.

\section{Medical device's market}

In the last decade, the medical device's global market has been steadily growing; in 2009, it was estimated in more than \$222 billion USD [3] and it is expected to worth more than $\$ 289$ billion USD by 2011 [4]. This growth can be explained by an increase of the global healthcare demand and by the aging of the population and the evolution of illnesses from acute and infectious types towards chronic ones.

The development of medical devices is technologically intensive. A typical company starts as a university spin-off relying in a single device or technology, to only then grow to a diversified organization [5]. In this sector, mergers and strategic alliances are quite common because they represent quick and effective ways of manufacturers to gain new product lines and technologies and enter new markets.

Besides the clinical and non-clinical studies medical devices are subjected before entering the market to demonstrate quality, safety, and efficacy, proofs of costeffectiveness are required. This evaluation is important since it creates expectations regarding the quality of the 
medical care and the efficacy of the treatment. In addition, national healthcare services and insurances systems use the result to decide if coverage is provided. Coverage and reimbursement decisions impact directly on the manufacturers' attainable revenues.

As medical devices are highly substitutable by similar products with superior efficacy, profits depend on new solutions which compel manufacturers to be constantly innovating, researching and presenting new solutions.

\section{E. Medical device's users}

Medical device users are extremely heterogeneous. For example, doctors, nurses and patients can be quoted as only few within the myriad of possible users. Besides the variety, each group has a distinctive perspective given the fact the device is used differently and with dissimilar expectations by each of them. Furthermore, the passage and sales method differs from the ones used by other industries.

In their work, Shah et al [6] presented a definition and a classification for medical device's users (Fig.1). The authors distinguish medical device user from end-user. The first refers to 'a person who uses a medical device for the treatment and/or care of him- /her-self or someone else', while the second refers to 'a person who is the ultimate beneficiary of the usage of a medical device and who can also be the user of a medical device if using the medical device for him- /her-self'.

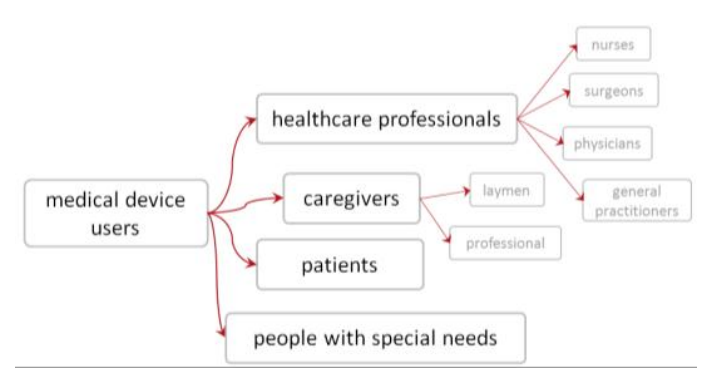

Fig. 1 Medical device users (adapted from [6])

\section{F. Product development}

Product development refers to the process of creating products with new or different characteristics to offer fresh or additional features to customers. While some authors describe this process with only 5 steps, others name as many as 25 stages [7].

Normally, the development of a product is triggered by a need or an idea. Then, the design team identifies the specific problems that customers intend to solve purchasing a good or service (customer needs) and generate concepts. From the panoply of concepts, only one is developed and optimized. Following this, prototypes and/or small series are produced. These pre-series are evaluated by a restrict number of clients or by certifier companies. The process ends with the launch of the product in the market.

In spite of the design process being commonly represented in a linear fashion (as shown in Fig 2), the development of a product is an iterative process in which different steps can be performed simultaneously.

\section{Discussion}

Although the differences regarding medical device's definition and classification appear to be subtle, they affect how devices enter the market and even the company's strategy. For example, some US companies have branches in Europe because the approval process is faster and the data gathered can be used in the FDA's approval process. Other companies seek a certain classification for their devices so they can either be introduced faster in the market or force competition to go through time consuming clinical studies. However, this may change in the future since, in 1992, a Global Harmonization Task Force (GHTF) was formed with the goal to achieve greater uniformity between national medical device regulatory systems.

The definition of medical devices leads to an assorted and broad range of products with a wide diversity in risk and variable development time as well as variable production quantities. All this adds to the particularity that medical devices are sold, after the approval process finishes, primarily to entities that are not the end-user. Moreover, since medical devices are bought according to hospitals or governments politics, it becomes difficult, if not impossible, to use the same market strategies commonly used for other products. In this context, metrics such return on investment or units sold are inappropriate to measure a company's success.

As stated earlier, a typical medical device company relies in a single product or technology. Considering that postmarket surveillance is expensive and affects how companies are seen in the market and their products are accepted, the cost of failure can be very high. In order to survive, companies cannot afford a mistake and a methodic approach can ensure that every detail is addressed. Furthermore, such an approach is essential to comply with the regulations regarding quality.

As populations demand better health products and services, hospitals and governments struggle with rising costs and actively search technological innovations. Companies that are able to offer cheaper solutions will take the lead. A dedicated product development methodology will help to 
understand all the stakeholders' point of view and reduce development costs.

Several tools and strategies have been proposed to make product development more efficient. However, there is little evidence regarding their utility in the medical device sector [8]. The authors commonly believe that this can change if an appropriate nomenclature is adopted highlighting the importance of each step in the development of a novel device.

Fig. 2 depicts the different steps in the development of a medical device.

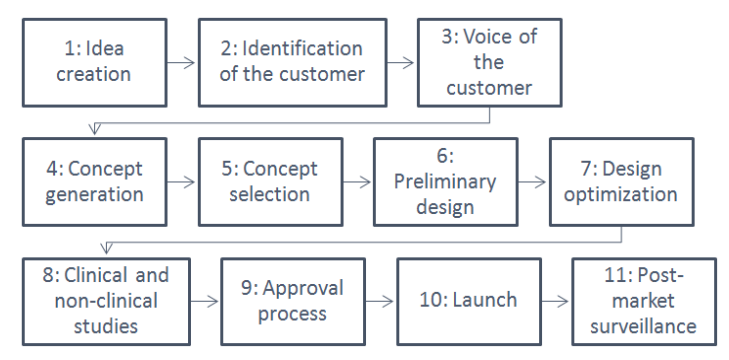

Fig. 2 Different steps of the medical device's development process

The identification of the customer is crucial; it is important to understand who will select the device and what arguments will be used to make a decision.

The voice of customer is the step in which the needs are gathered. In this stage, designers will have to consider the devices' learning curve and "wear the user's shoes", that is, they will have to understand the user's limitations and desires.

Concept selection is another crucial step because from this point onward, the design team is committed to a concept whose modification implies delays and additional costs. The decision made at this point should consider that the introduction of a sophisticated technology does not guarantee high-quality patient care. It should also consider the diseases incidence, the class the device will have, uncertainties (during the development a new treatment can become available) and should guarantee that complies with the inspection process.

After the design of the device, the next steps are the clinical and non-clinical studies and the approval process. Special attention must be given to these steps because, unlike drugs, there is no placebo for medical devices. Furthermore, final appraisals cannot be generalized across health systems because they depend on local values, disease incidence, costs and resources.
After the device is launched, the post-market surveillance needs to be considered.

\section{CONCLUSIONS}

The medical device industry has unique features: product diversification, high uncertainty regarding research, high technological complexity, high likelihood of market closure and high threshold for product inspection. These characteristics justify the adoption of a dedicated approach.

The adoption of a dedicated methodology could contribute to reduce development costs, increase the devices acceptance, improve the device's safety and efficiency and reduce device recalls. This would improve the company's image and assist to obtain funds for further researches.

In spite of the advantages mentioned, data shows that methodologies are more widespread in academics rather than in manufacturers. Thus, an adequate methodology for the development of medical devices should be developed in a partnership with industry.

\section{ACKNOWLEDGMENTS}

The first author wishes to thank FCT - Fundação para a Ciência e Tecnologia, in Portugal, for the financial support provided by the $\mathrm{PhD}$ grant $\mathrm{SFRH} / \mathrm{BD} / 42967 / 2008$. This work is partially supported by FCT under the project MITPt/EDAM-EMD/0007/2008.

\section{REFERENCES}

1. WHO Media centre (2010) Medical devices - Fact sheet $\mathrm{N}^{\circ} 346$

2. WHO (2003) Medical device regulations: global over-view and guiding principles, WHO, Geneva

3. Jones Z., Woods E. et al (2010) Design of a pulse oximeter for price sensitive emerging markets. 32nd Annual International Conference of the IEEE EMBS, Buenos Aires, Argentina, pp. 1085-8

4. (2010) 2010 Taiwan industrial outlook, Program Office Department of Industrial Technology \& Ministry of Economic Affairs, Taiwan

5. Panescu D. (2009) Medical device development. Engineering in Medicine and Biology Society. EMBC 2009. Annual International Conference of the IEEE, pp. 5591-5594

6. Shah S. G. S et al (2008) Medical device technologies: who is the user?. International Journal of Healthcare Technology and Management, 9(2), pp. 181-197

7. Pahl G., Beitz W et al (2007) Engineering design - A systematic approach, Springer London, London

8. Eatock J., Dixon D., and Young T. (2009) An exploratory survey of current practice in the medical device industry. Journal of Manufacturing Technology Management, 20(2), pp. 218-234. 